\title{
A autoria no Sistema Nacional de Cultura sob o olhar da perspectiva bakhtiniana
}

\author{
Inti Anny Queiroz \\ Universidade de São Paulo (USP), São Paulo, São Paulo, Brasil \\ inti.queiroz@gmail.com \\ http://orcid.org/0000-0002-6484-2712
}

DOI: http://dx.doi.org/10.21165/el.v47i2.1916

\begin{abstract}
Resumo
No presente estudo, analisaremos os processos de criação e escrita do Sistema Nacional de Cultura, inseridos nas reflexões e tramitações dos marcos legais no Congresso Nacional brasileiro e as relações destes com o poder executivo. Essa análise será fundamentada na proposta teórica de Bakhtin que concebe o autor enquanto participante responsável e da ética da criação responsável. Buscaremos traçar os autores dos enunciados, suas relações discursivas, políticas e éticas, em cada um dos eventos e atos nos enunciados do legislativo relativos ao Sistema Nacional de Cultura (SNC) e suas respectivas tramitações. De acordo com os resultados de nosso estudo, os enunciados da esfera legislativa apresentaram não apenas autores individuais, mas também coautores e recebem influência ideológica de grupos políticos constituídos, de seus valores axiológicos e exotopias.
\end{abstract}

Palavras-chave: esfera político-cultural; autoria; Sistema Nacional de Cultura; Bakhtin.

The authorship in the National System of Culture under the Bakhtinian perspective

\begin{abstract}
In the present study, we will analyze the creation and writing processes of the National System of Culture, inserted in the reflections and procedures of the legal frameworks in the Brazilian National Congress and their relations with the executive branch. This analysis will be based on Bakhtin's theoretical proposal that understands the author as a responsible participant and the ethics of responsible creation. We will try to trace the statements authors, their discursive political and ethical relations, in each of the events and acts in the legislative utterances related to the National System of Culture (CNS) and their respective procedures. According to the results of our study, legislative utterances presented not only individual authors, but also co-authors and received ideological influence from constituted political groups, their axiological values and exotopies.
\end{abstract}

Keywords: political-cultural sphere; authorship; National System of Culture; Bakhtin.

\section{Introdução}

O presente artigo busca analisar a autoria de enunciados pertencentes ao Sistema Nacional de Cultura do ponto de vista das teorias do Círculo de Bakhtin. Os enunciados escolhidos para a análise pertencem à esfera legislativa e tiveram, ao longo dos processos de criação, tramitação e aprovação, uma série de autores e agentes responsáveis por suas construções. Observaremos os autores dos enunciados por meio de suas relações discursivas, políticas e éticas, em cada um dos eventos e dos atos dos enunciados 
legislativos, relativos ao Sistema Nacional de Cultura (SNC), levando em conta também suas respectivas tramitações.

A autoria de enunciados produzidos na esfera legislativa pode ser pensada por meio do teor do texto originalmente inscrito nos parlamentos, mas também pelas interferências ocorridas na proposta, já que este, antes de chegar a sua aprovação e redação final, passa por uma série de alterações e interações. Nossa hipótese é que, em decorrência das diferentes etapas das tramitações e interações ocorridas durante os processos, estes enunciados apresentam uma multiplicidade de autores, os quais influenciam no conteúdo dos enunciados com seus valores axiológicos e intenções político-ideológicas.

Neste estudo, escolhemos como corpus dois tipos de marcos legais: duas emendas constitucionais e uma lei regulamentar:

i) Emendas Constitucionais 48/2005 e 71/2012 da Constituição Federal, relativas às PECs 306/2000 e 416/2005 (34/2012) que tratam do Plano Nacional de Cultura e do Sistema Nacional de Cultura;

ii) Lei regulamentar do Plano Nacional de Cultura (Lei federal 12.243/2010).

A análise da autoria desses enunciados é relevante, pois a relação entre os autores e agentes envolvidos está na base estruturante do Sistema Nacional de Cultura, que determina a participação social em sua construção. Os três enunciados selecionados compõem o mais alto grau legal e hierárquico do novo modelo de política cultural proposto no início do século XXI e regem os discursos de uma série de marcos legais regionais e manuais que foram produzidos nos anos seguintes. É possível dizer que ambos servem como lastro ideológico e base discursiva para a criação de um compêndio desses outros enunciados previstos para estruturar o Sistema Nacional de Cultura por todo o país.

Para a análise do corpus utilizaremos como fundamentação teórica o conceito de autor presente nas seguintes obras de Mikhail Bakhtin, enumeradas na ordem de sua escrita e/ou publicação: $O$ problema do conteúdo do material e da forma na criação literária (1924); O autor e a personagem na atividade estética (1924-27); O discurso no romance (1934-35); Problemas na poética de Dostoiévski (1963) e Os Gêneros do discurso (1951-53). Ainda que em boa parte dessas obras Bakhtin trate do conceito de autoria a partir da análise da esfera literária, buscaremos compreender como o conceito pode incidir sobre as demais esferas da vida e identificar os conceitos-chave relacionados, como veremos a seguir. Acreditamos que a teoria de Bakhtin poderá nos auxiliar nos objetivos desta análise por compreender que a autoria não é construída apenas por um indivíduo, mas por um autor ser responsável e participativo (ou autores) em diálogo com o mundo social que o rodeia e que cria enunciados impregnados de vozes sociais e discursos de enunciados anteriores.

O artigo será desenvolvido em três partes. Primeiramente, trataremos do conceito de autoria nas obras de Bakhtin. Em seguida, partiremos para a reflexão acerca da criação e autoria nos enunciados na esfera legislativa. E, finalmente, trataremos da análise e reflexão sobre a autoria nos enunciados legislativos do Sistema Nacional de Cultura. 


\section{O conceito de autoria nas teorias de Bakhtin}

O conceito de autoria nas obras de Mikhail Bakhtin foi sendo desenvolvido ao longo de décadas e pode ser pensado como uma chave para a arquitetônica de sua teoria. Nas primeiras obras do pensador russo, Arte e responsabilidade e Para uma filosofia do ato responsável, a autoria ainda não estava no foco, porém é possível dizer que, ao pensar a responsabilidade do ato ético do ser, Bakhtin já projetava o que viria a ser esse autor que é responsável por seus atos criativos no mundo da vida e da arte. "Arte e vida não são a mesma coisa, mas devem tornar-se algo singular em mim, na unidade da minha responsabilidade" (BAKHTIN, 2010b, p. XXXIV).

Na obra $O$ problema do conteúdo, do material e da forma na criação literária da metade dos anos 1920, Bakhtin passa a tratar do autor-criador de uma obra em diálogo aberto com os formalistas russos. Para ele, o autor-criador é um momento constitutivo da forma artística, pois é a "ponte" para o diálogo axiológico com o conteúdo, ao assumir um posicionamento valorativo em relação ao material e à forma. Nesta obra, Bakhtin também aborda outras esferas, como a científica e a política, e trata da autoria nestas outras esferas observando a ética e as relações axiológicas com o conteúdo. Isto é, a relação axiológica ativa pressupõe que o autor-criador se expressa através da forma, mas é por seu conteúdo e sua relação com outros discursos, que apresenta seus valores, sua ética e sua responsabilidade.

O autor-criador é um momento constitutivo da forma artística. Eu devo experimentar a forma como minha relação axiológica ativa com o conteúdo, para prová-la esteticamente: é na forma e pela forma que eu canto, narro, represento, por meio da forma eu expresso meu amor, minha certeza, minha adesão. (BAKHTIN, 2010, p. 58).

Ainda nos anos 1920, em seu ensaio O autor e a personagem, Bakhtin (2010b, p. 10) diz que o "Autor: é o agente da unidade tensamente ativa do todo acabado, do todo da personagem, do todo da obra, e este é transgrediente a cada elemento particular desta.". Neste ensaio, Bakhtin trabalha com a diferenciação entre o autor-pessoa e autor-criador. $\mathrm{O}$ autor-pessoa se confunde com a pessoa em si e suas experiências na vida e, para Bakhtin, é um tanto "ingênuo". O autor-criador de um determinado enunciado literário tem a possibilidade de uma visão exterior da obra e com isso pode fornecer a esta um acabamento. Ainda que nesta reflexão ele trabalhe o conceito de autoria principalmente em enunciados artísticos, o conceito de excedente de visão evidencia que, no caso de enunciados não artísticos, o acabamento só será possível por meio do olhar do outro.

Esse excedente da minha visão, do meu conhecimento, da minha posse - excedente sempre presente em face de qualquer outro indivíduo - é condicionado pela singularidade e pela insubstitutibilidade do meu lugar no mundo: porque nesse momento e nesse lugar, em que sou o único a estar situado em dado conjunto de circunstâncias, todos os outros estão fora de mim. (BAKHTIN, 2010b, p. 21).

No texto dos anos 1930, O discurso no romance, Bakhtin faz a relação do conceito de autoria com o de heterodiscurso, carregado de vozes sociais. Aqui o autor-criador é aquele que dá sua voz social ao todo artístico ainda que saiba que este discurso esteja impregnado de vozes de outros anteriores a ele. 
Conceber seu objeto pelo discurso é um ato complexo: por um lado, todo objeto precondicionado e contestado é elucidado, por outro, é obscurecido pela opinião social heterodiscursiva, pelo discurso do outro sobre ele, e nesse complexo jogo de claro-escuro entra o discurso que dele se impregna, que nele lapida seus próprios contornos semânticos e estilísticos. (BAKHTIN, 2015, p. 49).

O heterodiscurso introduzido no romance é aí submetido a uma elaboração literária. As vozes históricas e sociais que povoam a língua fornecem-lhe percepções concretas, organizam-se no romance em um harmonioso sistema estilístico que traduz a posição socioideológica diferenciada do autor e de seu grupo no heterodiscurso da época. (Ibidem, p. 78).

A assinatura do autor-criador de um enunciado carrega uma carga de responsabilidade para o futuro deste, seja em seus resultados imediatos ou num futuro mais distante, pois as respostas a ele virão de algum modo. Ao assinar um enunciado, o autor assume sua responsabilidade na autoria e perante o mundo, pois como ele mesmo diz a vida, a existência, não tem álibi.

No texto dos anos 1954-56, Os gêneros do discurso, Bakhtin relaciona a autoria aos limites do enunciado e a sua conclusibilidade, bem como amplia a sua reflexão para esferas não literárias, como a científica:

O objeto é objetivamente inexaurível, mas ao se tornar tema do enunciado (por exemplo, de um trabalho científico) ele ganha uma relativa conclusibilidade em determinadas condições, em certa situação do problema, em um dado material, em determinados objetivos colocados pelo autor, isto é, já no âmbito de uma ideia definida do autor. (BAKHTIN, 2010b, p. 281).

Ainda em relação à autoria, no ensaio Os gêneros do discurso, Bakhtin trata do tema e a correlaciona com os gêneros discursivos e com as diferentes posições sociais de cada tipo de autor. Em cada esfera e em cada gênero, temos tipos diferentes de autoria que dialogam com as especificidades do enunciado.

A questão do falante (do homem, do sujeito do discurso, do autor do enunciado, etc.). A linguística conhece apenas o sistema da língua e o texto. Por outro lado, todo enunciado, até uma saudação padronizada, possui uma determinada forma de autor (e de destinatário). (BAKHTIN, 2010b, p. 382).

A forma de autoria depende do gênero do enunciado. Por sua vez, o gênero é determinado pelo objeto, pelo fim e pela situação do enunciado. As formas de autoria e o lugar (posição) ocupado na hierarquia pelo falante (líder, czar, juiz, guerreiro, sacerdote, mestre, homem privado, pai, filho, marido, esposa, irmão, etc.). A posição hierárquica correlativa do destinatário do enunciado (súdito, réu, aluno, filho, etc.). Quem fala e a quem se fala. Tudo isso determina o gênero, o tom, e o estilo do enunciado: a palavra do líder, a palavra do juiz, a palavra do mestre, a palavra do pai, etc. É isso o que determina a forma da autoria. A mesma pessoa real pode manifestar-se em diversas formas autorais. (Ibidem, p. 389-390).

É possível dizer que, nas reflexões de Bakhtin, encontramos diferentes formulações sobre a autoria: a de autor-criador, como aquele que cria esteticamente com base em suas posições valorativas e assim confere acabamento da obra estética, principalmente no âmbito da esfera literária, mas também de um autor que participa 
ativamente de um ato nas demais esferas da vida, que, ao criar um determinado enunciado, realiza um ato ético responsável.

Em síntese, embora um enunciado possua um autor, a sua voz não é a única; é possível "escutar outras vozes" sociais em diálogo polêmico com o projeto de dizer e as possíveis ressonâncias no público presumido que receberá este enunciado. Essa "bagagem" de outras vozes impregnadas nos enunciados evidencia o que Bakhtin, na Obra Problemas da Poética de Dostoievski chama de "relações dialógicas" que:

[...] devem personificar-se na linguagem, tornar-se enunciados, converter-se em posições de diferentes sujeitos expressas na linguagem para que entre eles surjam relações dialógicas. (BAKHTIN, 2010c, p. 209)

[...] devem tornar-se discurso, ou seja, enunciado, e ganhar autor, criador de dado enunciado cuja posição ele expressa. [...] são possíveis não apenas entre enunciações integrais (relativamente), mas o enfoque dialógico é possível a qualquer parte significante do enunciado, inclusive uma palavra isolada. (BAKHTIN, 2010c, p. 210).

O conceito de autor está na centralidade da definição dos limites do enunciado e do seu conteúdo. É o autor-criador quem dá o primeiro acabamento ao enunciado, no caso de um enunciado artístico, por meio de sua forma arquitetônica, de seu tom emotivovolitivo, de sua criação numa totalidade organizada pela expressão. Essa forma arquitetônica traz a singularidade do enunciado e mostra não apenas sua forma, mas principalmente o conteúdo valorado deste enunciado, os valores axiológicos de seu autorcriador. É relevante observarmos a atividade totalizante do autor que, numa dada esfera de produção, num momento único da história, em uma situação de comunicação, num horizonte social específico, dá acabamento ao objeto de dizer. No caso de um enunciado não artístico, esse acabamento é possível a partir da relação com o outro ou com outros enunciados e discursos. Este autor se relaciona com outros enunciados anteriores e com outras vozes, que acabam por impregnar quase involuntariamente o enunciado que está sendo criado.

O enunciado vivo, que surgiu de modo consciente num determinado momento histórico em um meio social determinado, não pode deixar de tocar as milhares de linhas dialógicas vivas envoltas pela consciência socioideológica no entorno de um dado objeto da enunciação, não pode deixar de ser participante ativo do diálogo social. É disto que ele surge, desse diálogo, como sua continuidade, como uma réplica e não como se ele se relacionasse à parte. (BAKHTIN, 2015, p. 49).

Como vimos, às diferentes esferas compreendem diferentes processos autorais. No caso da esfera legislativa, a autoria está diretamente relacionada com outros discursos sociais existentes, com o ato ético responsável de seus autores diretos e da sua relação com os outros agentes participantes dos processos, como veremos a seguir.

\section{A autoria na esfera legislativa}

Para melhor compreender a autoria nos enunciados de nosso corpus é relevante refletir acerca de como são construídos esses marcos legais na esfera legislativa. No caso, buscaremos compreender como são criados e aprovados dois tipos de enunciados: as 
Propostas de Emendas Constitucionais (PECs) e as leis, e como são compostas suas múltiplas autorias.

As Emendas Constitucionais (EC) são instrumentos legais para realizar adições e mudanças em artigos da Constituição Federal (CF) vigente e são instituídas por meio de Propostas de Emendas Constitucionais (PEC). Apenas as chamadas Cláusulas Pétreas não podem ser alteradas e nem abolidas por ECs. Nas demais partes da CF, as emendas constitucionais podem alterar pequenos trechos ou mesmo inserir novos artigos e parágrafos a capítulos já existentes. Na criação de um marco legal está intrínseca a presença de pelo menos um autor que assinará sua autoria e assim, por meio de um ato no mundo, criará uma nova unidade de cultura na esfera legislativa.

Podemos considerar que, num processo legislativo básico, teremos sujeitos em interação e as seguintes vozes: a voz do(s) autor(es) da lei, as vozes dos respectivos assessores parlamentares que auxiliam na escrita dos enunciados legislativos, as vozes das deliberações de seus relatores (às vezes, expressas em emendas e textos substitutivos), dos convidados de audiências nas diversas comissões em que foram analisadas ou mesmo as vozes dos vetos posteriores ou a não sanção da lei pelo Presidente da República, o chefe do poder executivo.

Há casos em que os projetos de leis são discutidos e votados não por seu teor completo, mas por artigos. Nesses processos, o voto dos parlamentares presentes na plenária poderá aprovar ou não determinados trechos destes marcos legais. Em alguns casos, novas leis e PECs poderão alterar o texto do que foi determinado em um dado enunciado legislativo no passado, de acordo com diferentes conjunturas, interesses e desacordos políticos. Isto é, uma lei, ainda que tenha um autor inicial proponente, é um tipo de enunciado que, em boa parte dos casos quando há maior disputa política, pode revelar diversas vozes e poderá ser alterada ao longo do trâmite e do tempo, através de demandas sociais ou apenas da necessidade de sua atualização. Esse tipo de tramitação evidencia que os marcos legais são enunciados com alto teor dialógico.

Ainda é preciso levar em conta que, na esfera legislativa, por seu caráter político, a disputa partidária influencia diretamente nos trâmites e interações relativos às leis. As relações entre os grupos políticos, ou como são chamadas, as bancadas parlamentares, são fatores que devem ser levados em conta ao observarmos a trajetória de uma determinada lei. Conseguir apoio nos mais diversos grupos políticos é de extrema importância para que um marco legal consiga ser aprovado com mais facilidade, e principalmente, para chegar ao final do processo com uma redação final que mantenha as intenções político-ideológicas de seu autor inicial.

O ato ético bakhtiniano pressupõe um dever ser com vistas ao outro e em relação com todos os pontos da arquitetônica. Devo pensar sobre qual é de fato o modo correto de agir, para mim e para o outro, de modo prático e em relação ao contexto. Ao criar uma lei, não são as necessidades e vontades individuais do sujeito parlamentar que devem imperar e sim o que na prática beneficiará a coletividade de pessoas que o elegeram. Os eleitores representam diretamente "o outro" de um parlamentar autor de uma determinada proposta na esfera legislativa.

Estes agentes (autor da lei, relatores, demais parlamentares, ministros e presidente da república) atuam conjuntamente para compor a escrita de marcos legais que devem estar de acordo com os preceitos éticos e políticos de um determinado país, e, no caso do Brasil atual, de acordo com a Constituição Federal vigente de 1988. Nos dias atuais, 
contamos com ferramentas mais democráticas de interação e participação social, como as consultas públicas feitas via internet nos sites do Congresso Nacional, em que a sociedade civil pode opinar se é a favor ou contra determinada proposta legislativa ou mesmo sugerir alterações em trechos de alguns marcos legais, como já ocorreu em diversos processos legislativos.

É possível aferir que os marcos legais, por conta de seu caráter ético e político, trazem em seu conteúdo forte teor ideológico, ao abordar nestes enunciados pontos de vista sobre determinado tema social que atingirá milhares de pessoas. O teor ideológico das deliberações em plenária e do conteúdo dos enunciados produzidos na esfera demonstra com maior clareza as diferentes avaliações sociais e a ética dos envolvidos, as diferenças de interesses políticos e econômicos, mesmo que estes nem sempre prezem pela ética coletiva. Os valores inseridos nestes enunciados determinarão a forma do conteúdo relacionado à arquitetônica de um enunciado da esfera.

Nos conteúdos dos marcos legais, percebemos as intenções éticas dos interlocutores e autores. "[...] o conteúdo, em sua base, é ético" (BAKHTIN, 2010c, p. 21). Cada partido ou grupo político tem declaradamente tipos diferentes de visões de mundo, isto é, tem distintas avaliações sociais. É possível dizer que cada parlamentar está relativamente sincronizado ideologicamente com a proposta de seu grupo político ou partido e suas propostas legislativas podem ser observadas também levando em conta o grupo político-ideológico a que pertencem e os valores axiológicos defendidos em conjunto.

Toda enunciação verbalizada do homem é uma pequena construção ideológica. A motivação do meu ato é, em pequena escala, uma criação jurídica e moral; uma exclamação de alegria ou tristeza é uma obra lírica primitiva; as considerações espontâneas sobre as causas e efeitos de fenômenos são embriões de conhecimentos científicos, filosóficos etc. Os sistemas ideológicos estáveis e enformados das ciências, das artes, do direito etc. cresceram e se cristalizaram a partir do elemento ideológico instável, que através das ondas vastas dos discursos interior e exterior banham cada ato nosso e cada recepção nossa. Evidentemente, a ideologia enformada exerce, por sua vez, uma poderosa influência reflexa em todas as nossas reações verbalizadas. (BAKHTIN, 2009, p. 88).

Contudo, ainda que este receba influências de seu grupo e da esfera, o ponto de vista e os valores axiológicos do autor inicial também estarão refletidos no enunciado que está sendo criado. O autor é constitutivo do enunciado criado. Seus valores estão presentes em seu conteúdo e em diálogo com outros discursos anteriores. Bakhtin (2010, p. 29-30) em $O$ problema do conteúdo do material e da forma na atividade estética diz que

[...] nenhum ato cultural criador tem relação com uma matéria indiferente a valores, totalmente casual e desordenada [...] ele se relaciona com algo já apreciado e de certa forma ordenado, perante o qual agora ele deve ocupar com conhecimento de causa, sua posição axiológica.

Para Bakhtin, o autor ou os autores não estão indiferentes ao que está sendo criado. Estes têm intenção, vontade e apreço ideológico por aquilo que estão compondo, um enunciado pleno de valores axiológicos. $\mathrm{O}$ autor é responsável por aquilo que está criando em seu ato criativo e ético. De acordo com Bakhtin, a relação do autor com a realidade pré-existente no ato ético é diferente da relação puramente estética. No ato ético, esta 
relação "é habitualmente expressa como a relação do dever para com a realidade" (BAKHTIN, 2010, p. 32).

O entendimento de que a esfera legislativa brasileira tem sua estrutura e seu modus operandi específicos, bem como uma hierarquia interior e uma relação com os três poderes da República, deve ser levado em conta em nossa análise. A autoria na esfera legislativa, principalmente em tramitações com maior disputa política, pode se revelar como um "quebra-cabeças" com diversas vozes que trazem valores axiológicos e interesses políticos distintos e que, algumas vezes, são impossíveis de conhecer. A esfera legislativa, por conta de seu caráter institucional e político-partidário, e por ser permeada por interesses dos mais diversos grupos sociais, faz ecoar vozes diversas em disputa num só processo de criação de um enunciado. Com isso, podemos aferir que o processo de construção arquitetônica de um enunciado nessa esfera pode demonstrar o diálogo de diversas consciências, com fortes posições avaliativas, em que os fatores ideológico e ético são uma mistura de valores individuais, de grupos políticos e da sociedade civil. No Brasil, a esfera legislativa se nomeia como democrática e assim assume como característica enunciados compostos por sujeitos em interação. Como em outras esferas ideológicas, deve-se levar em conta a relação dos autores com os outros interlocutores, a situação de comunicação, o gênero e suas especificidades, a relação com outras esferas de produção e circulação de determinado enunciado, e os outros diferentes enunciados produzidos em diálogo durante o processo. Todos esses fatores incidem na autoria e na criação do enunciado.

\section{A autoria no Sistema Nacional de Cultura}

O primeiro marco legal que inicia os processos de construção do Sistema Nacional de Cultura foi a PEC 306/2000 relativa ao Plano Nacional de Cultura que busca inserir o parágrafo $3^{\circ}$ ao artigo 215 da Constituição Federal. A apresentação da proposta ocorreu no dia 29 de novembro de 2000 pelo Deputado Federal Gilmar Machado (PT - MG). A criação da PEC vem de um processo de discussões anteriores ao ano 2000 e que se fortificaram em uma conferência realizada na Comissão de Educação e Cultura da Câmara Legislativa a partir de 1998. Na época, Gilmar Machado estava em diálogo com outros parlamentares e também com intelectuais e artistas. O processo de criação da PEC foi construído de forma dialógica, a partir dos debates da conferência e da comissão, isto é, com diversas pessoas em diferentes etapas da interação. A PEC foi aprovada e transformada em Emenda Constitucional N. 48 no dia 10 de agosto de 2005. Seu teor inseriu no artigo 215 (já existente e que trata da garantia do pleno exercício dos direitos culturais) o terceiro parágrafo que diz o seguinte:

$\S 3^{\circ}$ A lei estabelecerá o Plano Nacional de Cultura, de duração plurianual, visando ao desenvolvimento cultural do País e à integração das ações do poder público que conduzem à: I - defesa e valorização do patrimônio cultural brasileiro; II - produção, promoção e difusão de bens culturais; III - formação de pessoal qualificado para a gestão da cultura em suas múltiplas dimensões; IV - democratização do acesso aos bens de cultura; V - valorização da diversidade étnica e regional. (BRASIL, 2005).

Apesar de sua escrita resumida e até certo ponto de caráter abrangente, o trecho acima traz ênfases valorativas que podem demonstrar que o autor da PEC, quando da sua criação, levou em conta não apenas a complexidade da esfera da cultura como um todo, 
mas pensou também na complexidade da gestão da cultura, entendida a partir deste momento pelo olhar da política cultural e escutou as necessidades da esfera. Essa afirmação fica mais evidente nos trechos em que se ocupa da formação para gestão da cultura e da democratização do acesso. A partir daquele momento não apenas a arte e o patrimônio estavam em pauta, mas um caráter mais político-social da cultura, visando a democratização do acesso e a diversidade. Essa visão da cultura também demonstra o interesse do autor em possibilitar que a esfera político-cultural, através daquela proposta, pudesse ser repensada como processo de gestão pública e para isso acontecer seria necessário levar em conta a formação de gestores especializados nas práticas de um setor complexo e diferente como a cultura. Assim, Gilmar Machado apresenta por meio do parágrafo da EC seus valores axiológicos e seu entendimento sobre a política cultural, porém com influência de outros discursos, já que o enunciado foi criado a partir dos debates em audiências públicas feitas no Congresso.

O segundo enunciado presente em nosso corpus é o Projeto de Lei de regulamentação do Plano Nacional de Cultura (PL 6.835/2006) que depois de aprovado tornou-se a Lei Federal 12.243/2010. O texto inicial da lei regulamentar do PNC foi assinado pelo deputado Gilmar Machado, mas contou com importantes contribuições dos deputados Paulo Rubem Santiago (PT-PE) e Iara Bernardi (PT-SP) que assinam em parceria. Ao observarmos o processo de tramitação do projeto da lei do PNC pelo site da Câmara Federal, desde o início é possível perceber que o texto proposto pelos três autores originais não apresentou o formato de enunciado de lei conforme aprovada, mas sim uma proposta do que seria o Plano, com justificativas, detalhes do que estavam propondo e até a metodologia da implantação e das conferências. O texto inicial do PL tinha 21 páginas e ainda não estava escrito em formato de lei, mas num texto corrente e apresentava como introdução uma breve contextualização social e histórica para justificar a proposta.

A história demonstra que tem havido um processo de exclusão da maioria de nossa população. Nossas crianças e nossos jovens, embora herdeiros de um grande patrimônio cultural e criativos o suficiente para enriquecê-lo e legar às gerações que virão, não conseguem ver seu próprio rosto na grande produção cultural dominante. A política cultural tem sido privilégio de poucos que dividem entre si os recursos, sejam públicos ou privados, destinados à criação e produção cultural. A I Conferência Nacional de Cultura, organizada desde a base, nos municípios, estados e regiões, congregando os diferentes atores, públicos e privados, discutiram profundamente questões centrais como gestão pública e cultura, cultura e direito à cidadania, economia da cultura, patrimônio cultural, comunicação e cultura, a democratização e descentralização dos meios de comunicação, o sistema nacional de cultura, entre outros pontos e deliberou pelas diretrizes que devem nortear a política cultural brasileira, constituindo-se no Plano Nacional de Cultura com suas metas bem definidas. Desta forma, apresento aos nossos pares esta proposta do Plano Nacional de Cultura, em anexo, resultado de um amplo debate em todo o País. Tenho a certeza que receberá a acolhida dos nobres deputados. ${ }^{1}$

Nas primeiras linhas da justificativa, os autores demonstram quais são seus valores axiológicos sobre a esfera político-cultural brasileira. Falam do tema "exclusão" como princípio justificador, e com forte tom de denúncia social nos trechos: "tem havido um processo de exclusão da maioria de nossa população", "não conseguem ver seu próprio rosto na grande produção cultural dominante", "A política cultural tem sido privilégio de

\footnotetext{
${ }^{1}$ Texto disponível em: <http://imagem.camara.gov.br/Imagem/d/pdf/DCD19ABR2006.pdf\#page=160>. Acesso em: 22 set. 2016.
} 
poucos que dividem entre si os recursos, sejam públicos ou privados". Aqui percebemos o embate entre os conceitos de exclusão/inclusão e privilegiados/desprivilegiados. Os autores trazem neste trecho uma justificativa ética essencial para nossa reflexão, pois apontam que o PNC poderia ser uma possibilidade de "direito à cidadania", de "democratização" e de inclusão.

A construção do marco legal passou por diversas etapas ao longo dos cinco anos até sua aprovação. Uma das mais importantes foi a consulta pública realizada no ano de 2008 em 27 seminários em todos estados do país e com participação de mais de cinco mil pessoas. Isso nos faz pensar num processo com influência da sociedade civil por meio da participação de centenas de coautores, o que evidencia o caráter dialógico e plural dos enunciados analisados.

Em abril de 2009, a deputada Fatima Bezerra (PT - RN) é designada pela comissão como nova relatora do PL. No mês de setembro, Fatima apresenta um parecer com uma extensa reflexão sobre o PNC e, junto a ele, um novo texto substitutivo, em formato de projeto de lei. Neste momento, é criado o enunciado no formato do gênero projeto de lei regulamentar da Câmara, através das reflexões existentes no extenso texto dos deputados autores iniciais. Nas justificativas ao PL, Fatima demonstra conhecer em profundidade o tema da gestão da cultura e toma para si a responsabilidade ética pela aprovação do PL ao participar de forma ativa e interessada do processo com uma vasta pesquisa em seu relatório. Ao longo do enunciado, cita e comenta trechos de diversos documentos relacionados como os resultados da I CNC, os documentos mexicanos da UNESCO (Declaração do México e Nuestra Diversidad Creativa), a Agenda 21 da Cultura, a Convenção para a Proteção e a Promoção da Diversidade das Expressões Culturais etc. Além disso, também faz referências a reflexões de pensadores brasileiros da cultura como a historiadora Lia Calabre e o gestor e ator Sergio Mamberti, a fim de complementar sua argumentação. O documento de autoria de Fatima Bezerra apresenta, além das reflexões e do texto da lei, também os anexos contendo as diretrizes, estratégias e ações do PNC. Isso leva a crer que os textos, tanto da lei quanto dos anexos, foram escritos em parceria com membros do Ministério da Cultura, por meio das discussões, reuniões e encontros realizados com a sociedade civil. Essa parceria é evidenciada pela menção e diálogo com a publicação Porque aprovar o Plano Nacional de Cultura de abril de 2009, mesmo período em que se inicia o processo de relatoria de Fatima na Comissão de Educação e Cultura. A publicação foi desenvolvida pelo MinC com a intenção de auxiliar a compreensão da estrutura e do funcionamento do plano e do sistema como um todo, endereçado tanto para a sociedade civil, quanto para os demais deputados da Câmara.

Depois do texto substitutivo proposto por Fatima Bezerra, o projeto de lei recebeu sete emendas parlamentares propostas pelo deputado Emiliano José (PT - BA) quando estava em análise na Comissão de Constituição e Justiça em dezembro de 2009. As emendas propunham pequenas alterações em diversos trechos do enunciado. As emendas propostas por Emiliano José resultaram em algumas alterações consideráveis no texto, por exemplo, no Art. $3^{\circ}$ Parágrafo $4^{\circ}$, que trata das atribuições do poder público. E no Art. $11^{\circ}$ que trata das disposições finais em seu Parágrafo único. 


\section{Art. $3^{\circ}$ Versão Deputada Fatima Bezerra.}

$\S 4^{\circ}$ Poderão colaborar com o Plano Nacional de Cultura, em caráter voluntário, outros entes, públicos e privados, tais como empresas, organizações corporativas e sindicais, organizações da sociedade civil, fundações, pessoas físicas e jurídicas que se mobilizem para a garantia dos princípios, objetivos, diretrizes e metas do PNC, estabelecendo termos de adesão específicos.

Art. $3^{\circ}$ Versão Deputado Emiliano José.

$\S 4^{\circ} \mathrm{O}$ Poder Executivo federal, observados os limites orçamentários e operacionais, poderá oferecer assistência técnica e financeira aos entes da federação que aderirem ao plano, nos termos de regulamento.

\section{Art. $11^{\circ}$ Versão Deputada Fatima Bezerra.}

Parágrafo único. A primeira revisão do plano será realizada após quatro anos da promulgação desta Lei e contará com a participação de especialistas, instituições culturais e órgãos do poder público, com o apoio da sociedade civil, do Conselho Nacional de Política Cultural e de outros órgãos colegiados de caráter consultivo, na forma do regulamento.

\section{Art. $11^{\circ}$ Versão Deputado Emiliano José.}

Parágrafo único. A primeira revisão do plano será realizada após quatro anos da promulgação desta Lei, assegurada a participação do Conselho Nacional de Política Cultural - CNPC e de ampla representação do poder público e da sociedade civil, na forma do regulamento. ${ }^{2}$

O documento contendo as emendas propostas pelo deputado Emiliano, além de alterar brevemente seis trechos da lei, sugeriu também um novo artigo ao enunciado que dá a competência aos entes federados de realizarem suas próprias conferências territoriais e setoriais.

Podemos aferir que a redação final do texto da lei 12.343/2010 foi um processo de escrita e criação na esfera legislativa composto por diversas consciências, com influência dos discursos e das discussões incentivadas pelo MinC e ocorridas na sociedade civil. Todavia, é relevante evidenciar que todos os cinco deputados que efetivamente participaram do processo de escrita eram do mesmo partido, o que demonstra uma linha ideológica de consenso ao longo do processo entre os principais coautores participantes. Ainda que tivesse sofrido um atraso considerável em seu processo entre 2007 e 2009, em nenhum momento o PL teve dificuldades para ser aprovado ou demonstrou problemas concretos de disputa política por trechos de seu conteúdo. O único embate político ocorrido no processo foi o requerimento 404/10 apresentado em 15 de abril de 2010 pelo deputado Milton Vieira (DEM - SP), alegando que a matéria deveria ser levada à ampla discussão na plenária da Câmara, pois era de interesse de "diversos segmentos da sociedade civil"? 3 . Após um requerimento do autor

\footnotetext{
2 Trechos disponíveis em:

$<\underline{\text { http://www.camara.gov.br/proposicoesWeb/prop_mostrarintegra?codteor }=752712 \text { \&filename }=\text { Tramitaca }}$ o-PL+6835/2006>. Acesso em: 23 set. 2016.

${ }^{3}$ Idem
} 
do PL, Gilmar Machado, prosseguiu para sua redação final e aprovação por unanimidade conforme substitutivos e emendas no dia 25 de novembro de 2010. No dia 02 de dezembro, o texto foi publicado no Diário Oficial da União (DOU) com a sanção presidencial de Lula.

A lei do PNC traz assim uma multiplicidade de autorias, ainda que em termos ideológicos tenha demonstrado consenso, por conta de todos os coautores serem do mesmo partido. Além de seu autor original, o deputado Gilmar Machado, é possível dizer que atuam como coautores na construção do enunciado os deputados Paulo Rubem Santiago, Iara Bernardi, Fatima Bezerra e Emiliano José. Todos os envolvidos estiveram empenhados no processo de diferentes formas como seres responsáveis em situações de comunicação únicas, para que este fosse aprovado conforme as discussões feitas junto à sociedade civil. Ainda que em termos político-ideológicos todos os envolvidos no processo tenham demonstrado convergência de ideias, é possível dizer que cada um deles trouxe uma contribuição diferente ao enunciado. A deputada Fátima Bezerra, por exemplo, ao atuar como relatora e criadora do texto substitutivo do PL já em formato de lei, pode ser vista como uma coautora com ampliada relevância perante os demais. Sua atuação na construção do enunciado deve ser pensada como uma segunda autoria, já que esta partiu de um texto justificativa, que trouxe as bases ideológicas do PNC, mas propôs um enunciado completamente novo, em outro gênero discursivo (lei) e com construção composicional diferente.

A contribuição do Deputado Emiliano José foi necessária para realizar pequenas modificações no marco legal antes de sua aprovação na Câmara dos Deputados. No documento das emendas presente na tramitação do PL no site do Congresso, não há justificativa a não ser de ajuste textual. Como acontece em muitos dos casos na esfera, para tornar a lei mais fácil de ser aprovada, ou mesmo para acertar questões legais, alguns ajustes nos enunciados são necessários antes de sua primeira votação no Congresso Nacional.

O terceiro momento de nossa reflexão busca analisar os processos e agentes participantes da criação e aprovação da Emenda Constitucional do Sistema Nacional de Cultura (SNC). A PEC 416/2005 do SNC foi inscrita na Câmara Federal pelo Deputado Paulo Pimenta (PT - RS) em junho de 2005 e visava inserir o novo sistema de cultura criando um novo artigo à $\mathrm{CF}$, o artigo 216-A. A estratégia de criar não apenas um novo parágrafo à $\mathrm{CF}$, mas um novo artigo, com teor distinto do artigo 216 que trata principalmente do patrimônio, demonstra que os autores da PEC do SNC buscavam ampliar o escopo da esfera político-cultural na carta régia.

No trâmite apresentado no site da Câmara Federal, é possível observarmos três versões diferentes da PEC 416/2005. O primeiro enunciado de junho de 2005, com autoria do Deputado Paulo Pimenta, trazia uma introdução menor sobre seu objeto e apenas cinco itens relativos ao Sistema. A segunda versão com o texto substitutivo proposto em abril de 2010, pelo então relator deputado Paulo Rubem Santiago (PT-PE) já demonstra a evolução da reflexão acerca do enunciado original. O deputado pernambucano buscou desenvolver o texto original de Paulo Pimenta para algo que trouxesse maior articulação com as discussões que estavam ocorrendo fora da esfera legislativa. Bem mais complexo que o enunciado anterior, este substitutivo traz quatro parágrafos diferentes distribuídos em 21 itens que tratam respectivamente dos princípios e diretrizes do sistema, da sua estrutura de gestão, da futura lei de regulamentação e dos sistemas nos entes federados. 
É relevante lembrar que Paulo Rubem Santiago também esteve envolvido no processo de escrita, relatoria e aprovação da lei regulamentar do PNC que começou quase simultaneamente em 2005. É possível ressaltar que a designação de Paulo Rubem em fevereiro de 2010 para a relatoria foi feita a partir da instituição de uma Comissão Especial para a discussão da PEC requerida pelo Deputado Odair Cunha (PT - MG). Essa comissão especial possibilitou a realização de audiências públicas para a discussão da matéria com participação de agentes de outras esferas, tanto do MinC quanto da sociedade civil.

Ainda em sua primeira etapa na Câmara dos Deputados, a PEC foi aprovada em primeiro turno por 361 votos a favor e apenas um voto contrário do Deputado Jair Bolsonaro (PP - RJ). No dia 26 de junho, a PEC foi discutida em sua $10^{\text {a }}$ sessão e aprovada em segundo turno por 326 votos a favor e um contra, do mesmo deputado carioca. Bolsonaro foi opositor a todas as matérias legislativas da área da cultura no período.

Em 28 de junho, a PEC foi enviada ao Senado para sua discussão final onde foi inscrita como PEC 34/2012 4 . Em agosto de 2012, a PEC foi submetida à Comissão de Constituição, Justiça e Cidadania do Senado Federal, na responsabilidade de relatoria da então senadora Marta Suplicy (neste momento ainda no PT - SP) que emitiu parecer favorável à proposta. No dia 12 de setembro de 2012, a PEC foi levada à discussão e votação e aprovada em primeiro turno por unanimidade pelos 56 senadores presentes e o segundo turno ocorreu na mesma data com 54 senadores. A sessão final de aprovação ocorreu na Câmara Federal em 29 de novembro de 2012 com a promulgação da Emenda Constitucional N. 71.

Ao atentarmos à autoria da $\mathrm{PEC}$ relativa ao $\mathrm{SNC}$ devemos reconstruir seu processo de criação, que, como vimos, foi fruto do trabalho de ações de diferentes autores (com discursos convergentes ideologicamente por serem todos do mesmo partido) e agentes da sociedade civil das mais diversas procedências. No texto de justificativa da PEC 416/2005 relativa ao SNC, seu autor inicial, o deputado Paulo Pimenta, escreveu:

Um sistema universalizador de gestão da cultura deve acolher, como elementos-chave, a criação dos conselhos de cultura, dos fundos de cultura e das formas de participação democrática e descentralizada dos produtores culturais e das comunidades em geral, além da atuação autônoma e articulada das três esferas de governo. Com isso, estabelecem-se as bases para implantar os componentes das políticas culturais: formação, criação, produção, distribuição, consumo, conservação e fomento. A partir desses elementos centrais, é possível pensar as políticas culturais como estratégias voltadas para o desenvolvimento cultural e econômico do País, para a garantia do direito de acesso aos bens culturais como prerrogativa essencial da população na construção da cidadania e para a defesa da diversidade cultural e das identidades culturais locais frente à globalização. Esta iniciativa vem complementar outras ações em tramitação nesta Casa com o objetivo de consolidar uma política cultural para o País. Uma delas é a Proposta de Emenda à Constituição n 306, de 2000, do Deputado Gilmar Machado e outros, que institui o Plano Nacional de Cultura, aprovada pelo Congresso em 2005. Outra iniciativa no mesmo sentido é a Proposta de Emenda à Constituição n ${ }^{\circ} 150$, de 2003, do Deputado Paulo Rocha e outros, que institui a vinculação de receita para a cultura, colocando em

\footnotetext{
${ }^{4}$ Ao tramitar da Câmara dos Deputados para a aprovação final no Senado, uma PEC recebe uma nova numeração a partir de sua ordem de inscrição.
} 
debate a questão do papel do Estado como fomentador das atividades culturais e da previsão orçamentária para a efetivação das políticas públicas de cultura. ${ }^{5}$

A citação à PEC 306/2000 feita na justificativa do deputado que consta em anexo ao enunciado da PEC 416/2005 e à PEC $150 / 2003^{6}$ nos leva a crer que o deputado Paulo Pimenta estava buscando não apenas demonstrar a relação dos enunciados dentro da arquitetura do sistema, mas principalmente incentivar a aprovação destas outras duas propostas por conta de seu caráter ético e democrático. A visão de Paulo Pimenta sobre o processo apontava para a construção do Sistema como um todo, isto é, para sua arquitetônica. Assim também foi a visão do deputado Paulo Rubem em seu texto substitutivo. Ambos estavam em diálogo constante com membros do MinC nos respectivos períodos, pois os discursos que traziam em seus relatórios, pareceres e justificativas eram semelhantes aos enunciados produzidos pelo MinC. Neste trecho da justificativa, Paulo Pimenta demonstra seus valores axiológicos e visão de política cultural quando diz que

A partir desses elementos centrais, é possível pensar as políticas culturais como estratégias voltadas para o desenvolvimento cultural e econômico do País, para a garantia do direito de acesso aos bens culturais como prerrogativa essencial da população na construção da cidadania e para a defesa da diversidade cultural e das identidades culturais locais frente à globalização. ${ }^{7}$

Para ele, as políticas culturais deveriam ser "estratégias" de desenvolvimento cultural e econômico, mas também a garantia do direito à cultura como essencial à cidadania e da defesa da diversidade. Mais uma vez vemos aqui os mesmos centros de valores apontados doze anos antes da PEC do PNC por Gilmar Machado, pois trata da gestão da cultura para o acesso e para a diversidade. Contudo, nesse novo momento, a ideia de política cultural como estratégia voltada para o desenvolvimento principalmente econômico parece estar se fortalecendo.

Podemos dizer que a autoria na Emenda Constitucional do SNC também se caracteriza com uma multiplicidade de autores do mesmo partido em diálogo para a construção do enunciado final. Ainda que haja diversos coautores participantes do processo, a voz socioideológica representa os valores do grupo, no caso do Partido dos Trabalhadores. Isso é evidenciado pelo fato de que as propostas do PNC e do SNC estão mencionadas no programa do partido para a eleição do Presidente Lula no ano de 2002. $\mathrm{O}$ autor inicial Paulo Pimenta assina a PEC, mas não podemos deixar de incluir como coautores Paulo Rubem Santiago e Marta Suplicy, ambos petistas naquele momento, que além de influenciarem como relatores no processo, também tomaram para si a responsabilidade para que esta pudesse tornar-se parte da Constituição Federal.

\footnotetext{
5 Justificativa à inscrição da PEC do SNC 416/2005. Disponível em: $<$ http://www.camara.gov.br/proposicoesWeb/prop_mostrarintegra;jsessionid=566A7270FAB7601DDE00 7C61F4608F0C.proposicoesWeb2? codteor $=316130 \&$ filename $=$ Tramitacao-PEC $+416 / 2005>$. Acesso em: 26 set. 2016.

${ }^{6}$ A PEC 150/2003 versa sobre a ampliação dos orçamentos de cultura nos três âmbitos de governo. Atualmente tramita com uma proposta substitutiva como PEC 421/2014 e aguarda apreciação.

${ }^{7}$ Idem nota 2.
} 


\section{Considerações finais}

Nos enunciados produzidos numa esfera de caráter normativo como a legislativa, os rastros da autoria são quase imperceptíveis ao longo dos textos em termos de estilo, mas estão marcados em seus conteúdos e no teor axiológico das proposições. Os deputados assinam a autoria e a relatoria nos marcos legais, porém, em boa parte dos casos, os textos legislativos são criados e escritos em conjunto com seus assessores em diálogo com as propostas político-ideológicas do partido a que pertencem. Partindo dessa situação de produção, é possível aferir que, dentre as vozes presentes nos enunciados analisados, devemos levar em conta os valores axiológicos destes agentes que se materializam nas entrelinhas desses enunciados. Os assessores especializados na escrita de marcos legais atuarão em diversas etapas dos processos de escrita e aprovação de uma determinada matéria. Ainda que esses assessores não assinem oficialmente a autoria dos enunciados e sejam anônimos nas informações publicadas, é possível dizer que são agentes de suma importância na criação e construção dos mesmos, tornando-se, assim, coautores anônimos de diversos marcos legais.

Os deputados, por assinarem a autoria e a relatoria destes marcos legais, assumem a responsabilidade ética pelo teor desses enunciados em relação ao mundo. Como evidenciou Bakhtin, a assinatura é a prova de que a vida não tem álibi e num enunciado reforça a responsabilidade pelo dito. Deste modo, há uma corresponsabilidade ética de parlamentares, assessores e sociedade civil no ato criativo responsável da escrita de uma lei ainda que alguns desses agentes permaneçam incógnitos e não participem da assinatura dos enunciados. No entanto, como vimos, a autoria se difere de assinatura nesses processos da esfera: há os processos em que autores assinam os marcos legais (seja como autor ou relator), e há os coautores que contribuem anonimamente, por exemplo, os assessores legislativos, cuja função é participar da escrita e revisão dos enunciados, ou mesmo agentes da sociedade civil presentes nas audiências.

Ao proporem os marcos legais analisados, os autores estavam em diálogo com outros marcos legais e discursos sociais e assim foram aos poucos construindo a arquitetônica desse novo sistema de gestão pública da cultura. Pudemos verificar que o SNC e seus autores estavam propondo uma forma de gestão e compreensão de cultura para a esfera político-cultural em termos de sua construção, na qual estavam presentes valores como possibilidade de democratização e de inclusão por meio da ampliação do acesso e da diversidade. Ao observarmos a construção histórica do Sistema e os personagens principais que atuaram na criação e composição desta arquitetura ao longo do tempo, foi possível verificar que o SNC e o PNC foram criados, construídos e pensados por diversos sujeitos autores. Entretanto, apesar da diversidade de autorias, constatamos um consenso político-ideológico de vozes nos enunciados, pois todos os autores principais eram do Partido dos Trabalhadores e criaram os enunciados de acordo com as propostas de gestão das políticas culturais do governo naquele período. 


\section{REFERÊNCIAS}

BAKHTIN, M. M. Teoria do romance I: A estilística. Tradução de Paulo Bezerra. Organização de Serguei Bocharov e Vadim Kojinov. São Paulo: Editora 34, 2015 [193435].

. O problema do conteúdo, do material e da forma na criação literária. In: . Questões de literatura e de estética. A teoria do romance. São Paulo: Hucitec, 2010 [1923-24]. p. 13-70.

Fontes, 2010b.

Estética da criação verbal. Tradução de Paulo Bezerra. São Paulo: Martins

Problemas da poética de Dostoiévski. Tradução de Paulo Bezerra. 5. ed. Rio de Janeiro: Forense Universitária, 2010c [1963].

Para uma filosofia do ato responsável. Tradução de Valdemir Miotello e Carlos Faraco. São Carlos: Pedro \& João Editores, 2010d [1920-24].

O freudismo: um esboço crítico. Tradução de Paulo Bezerra. São Paulo: Perspectiva, 2009 [1927].

BRASIL. PEC 416/2005. SNC. Institui o Sistema Nacional de Cultura. Disponível em: $<$ http://blogs.cultura.gov.br/snc/>. Acesso em: 10 mai. 2017.

. Lei $n^{\circ} 12.343$, de 2 dezembro 2010. Institui o Plano Nacional de Cultura PNC, cria o Sistema Nacional de informações e Indicadores Culturais - SNIIC e dá outras providências. 2010 .

Recebido em: 18/08/2017

Aprovado em: 15/07/2018 